\title{
Lipid, blood pressure and kidney update 2013
}

\author{
Maciej Banach • Corina Serban • Wilbert S. Aronow • \\ Jacek Rysz • Simona Dragan · Edgar V. Lerma • \\ Mugurel Apetrii $\cdot$ Adrian Covic
}

Received: 11 November 2013 / Accepted: 28 January 2014/ Published online: 27 February 2014

(C) The Author(s) 2014. This article is published with open access at Springerlink.com

\begin{abstract}
The year 2013 proved to be very exciting as far as landmark trials and new guidelines in the field of lipid disorders, blood pressure and kidney diseases. Among these are the International Atherosclerosis Society Global Recommendations for the Management of Dyslipidemia, European Society of Cardiology (ESC)/European Society of Hypertension Guidelines for the Management of Arterial Hypertension, American Diabetes Association Clinical Practice Recommendations, the Kidney Disease: Improving Global Outcomes Clinical Practice Guidelines for Managing Dyslipidemias in Chronic Kidney Disease (CKD) Patients, the American College of Cardiology/ American Heart Association Guideline on the Treatment of Blood Cholesterol to Reduce Atherosclerotic Cardiovascular Risk in Adults, the Joint National Committee Expert Panel (JNC 8) Evidence-Based Guideline for the Management of High Blood Pressure in Adults, the American
\end{abstract}

\footnotetext{
M. Banach $(\bowtie)$

Department of Hypertension, Chair of Nephrology

and Hypertension, Medical University of Lodz,

Zeromskiego 113, 90-549 Lodz, Poland

e-mail: maciej.banach@umed.lodz.pl

C. Serban

Department of Functional Sciences, Chair of Pathophysiology,

"Victor Babes" University of Medicine and Pharmacy

of Timisoara, Timisoara, Romania

W. S. Aronow

Cardiology Division, New York Medical College,

Valhalla NY, USA

J. Rysz

Department of Nephrology, Hypertension and Family Medicine, Chair of Nephrology and Hypertension, Medical University of Lodz, Lodz, Poland
}

Society of Hypertension/International Society of Hypertension Clinical Practice Guidelines for the Management of Hypertension in the Community, the American College of Physicians Clinical Practice Guideline on Screening, Monitoring, and Treatment of Stage 1-3 CKD and many important trials presented among others during the ESC Annual Congress in Amsterdam and the American Society of Nephrology Annual Meeting-Kidney Week in Atlanta, GA. The paper is an attempt to summarize the most important events and reports in the mentioned areas in the passing year.

Keywords Anemia - Blood pressure - Cholesterol . Dyslipidemia · Hypertension - Lipids · Renal disease . Transplantation

S. Dragan

Cardiology Department, University of Medicine and Pharmacy

"Victor Babes" Timisoara, Timisoara, Romania

E. V. Lerma

Section of Nephrology, University of Illinois at Chicago,

Chicago, IL, USA

M. Apetrii - A. Covic

Nephrology Clinic, Dialysis and Renal Transplant Center,

C.I. Parhon University Hospital, Iasi, Romania

M. Apetrii - A. Covic

Grigore. T. Popa University of Medicine and Pharmacy, Iasi, Romania 


\section{Lipid update 2013}

\section{LDL cholesterol and coronary risk}

In patients with multiple cardiovascular (CV) risk factors, it is essential to effectively manage the overall risk, in order to prevent CV events [1]. Traditionally, low-density lipoprotein cholesterol (LDL-C) and high-density lipoprotein cholesterol (HDL-C) have been considered as the classical biomarkers of risk assessment as well as the therapeutic targets in both primary and secondary prevention.

It is worth emphasizing that the current European Society of Cardiology (ESC)/European Atherosclerosis Society (EAS) guidelines (2011) indicate LDL-C as an only target for lipid disorders therapy [2]. Previous classification schemes and treatment levels for hyperlipidemia have been based on the National Cholesterol Education Panel's Adult Treatment Program-3 (ATP-III) guidelines. Interestingly, in November 2013, the Kidney Disease: Improving Global Outcomes (KDIGO) published a new evidence-based Clinical Practice Guideline making recommendations on treatment of dyslipidemias in chronic kidney disease (CKD) [3]. One of the highlights of this was the recommendation against the use of LDL-C for assessing coronary risk in patients with CKD. The reviewed published evidence showed weak and potentially misleading association between LDL-C and coronary risk particularly in those with CKD, thereby mitigating against the use of LDL-C for identifying CKD patients who should receive lipid-lowering therapies. Nevertheless, the KDIGO Work Group recommended that follow-up measurement of lipid levels should be reserved for instances in which the results would alter management, e.g., assessment of adherence to statin treatment, change in renal replacement modality or concern about the presence of new secondary causes of dyslipidemia, or assessment of 10-year CV risk in patients younger than 50 years who are not currently receiving a statin $[3,4]$.

Later that month, the American College of Cardiology (ACC) and the American Heart Association (AHA) published very expected clinical practice guidelines for the treatment of cholesterol in those at high risk of atherosclerotic cardiovascular diseases (ASCVD) [5]. Corollary to the KDIGO guidelines [3, 4], the ACC/AHA recommendations did not focus on specific target levels of LDL$\mathrm{C}$ and instead focused on four major groups of patients who are most likely to benefit from statin therapy, in terms of decreasing CV complications. These are: (1) patients with CVD, (2) patients with an LDL-C $190 \mathrm{mg} / \mathrm{dL}$ or higher, (3) patients with type 2 diabetes who are between 40 and 75 years of age and (4) patients with an estimated 10-year risk of CVD of $7.5 \%$ or higher (based on new risk equation) who are between 40 and 75 years of age [5]. New risk assessment tools have also been recommended to complement the guidelines when embarking on the decision whether or not to start patients on statins [5].

The large debate has started since the publishing of the new lipid guidelines. In the same month, the National Lipid Association (NLA) released a position statement expressing opposition to the former's recommendation to remove LDL-C (and non-HDL-C) treatment targets [6]. Also European Atherosclerotic Society (EAS) distanced from new ACC/AHA guidelines [7]. The European experts indicate that in the new American guidelines, statin treatment is recommended for primary prevention in subjects with a risk of ASCVD event of $7.5 \%$, irrespective of LDL$\mathrm{C}$ level, which would correspond to a moderate-2.5\% risk of CVD death in 10 years according to the European SCORE model. Therefore, they suggest that the impact of the ACC/AHA strategy should be put into the perspective of the very large number of subjects in the population who would be eligible for lifelong statin treatment from the age of 40 years onwards [7]. They also comment a new risk estimation model for estimating the total CVD risk (Pool cohorts equations) that has been developed in the new guidelines and suggest that from the available documents it cannot be evaluated how this would work in relation to the European SCORE model. Therefore, they suggest that for the European population the SCORE charts or national charts calibrated on SCORE should be still recommended [7]. Finally, EAS guideline committee comments no treatment goals of LDL-C in new ACC/AHA guidelines, although the option of having treatment goals has been accepted. They indicate that treatment goals are widely used in different clinical settings, such as for the treatment of arterial hypertension or type- 2 diabetes, and targets are a most important tool in daily practice, aiding patient-todoctor communications and optimizing compliance, and emphasize that risk reduction in general should be individualized for each patient, and this can be more specific if targets are defined [7]. Finally, they take a notice that the EAS/European Society of Cardiology (ESC) (2011) guidelines have a broader approach on dyslipidemia in general, while the ACC/AHA guidelines are focused on statin treatment in cardiovascular prevention. Therefore, in the EAS/ESC guidelines, special groups, such as individuals with familial hypercholesterolemia, combined hyperlipidaemia and diabetes, and stroke patients, are discussed more in detail. What is also very important the EAS/ESC guidelines also include a more in-depth discussion and options on drug treatments other than statins, while in ACC/AHA lipid guidelines no other lipid-lowering drugs (as well as the combined therapy) is discussed and recommended [7]. It is also worth mentioning the other limitations of the American guidelines: (1) lack of inclusion of all important randomized controlled trials (RCTs) on statin 
therapy and therapeutic goals (the selectivity of RCTs inclusion); (2) lack of information on management with patient with side effects of statin therapy (including management in patients with statin intolerance); (3) the arbitrarily accepted age limit for the elderly patients $(\geq 75)$ [8-11].

\section{New biomarkers of lipid disorders}

Considering the complicated mechanisms and signals involved in atherosclerosis, research is now focused on novel lipid biomarkers that can be introduced as routine diagnostic tests. It is important to determine whether adding information on apolipoprotein B (apoB) and apolipoprotein A1 (apoA1), lipoprotein (a) or lipoproteinassociated phospholipase A2 to total cholesterol (TC), LDL-C and HDL-C improves cardiovascular disease (CVD) risk prediction [12-14]. It is known that in selected individuals at high $\mathrm{CV}$ risk, despite LDL-C, triglycerides (TG) should be targeted, but HDL-C, Lp(a) and ratios such as LDL-C/HDL-C or apoB/apoA1 are not recommended as treatment targets [15]. We still do not have enough data for these biomarkers (or the existing data suggest that we should not use the given biomarker as a treatment target), or their measurements are still too expensive and therefore not cost-effective (like for apoB).

Different clinical conditions associated with inflammation, oxidation, advanced glycation and protein carbamylation, such as diabetes, coronary artery disease (CAD) or CKD can alter the functionality of HDL, converting normal HDL into so-called dysfunctional HDL which is no longer cardioprotective [16]. Furthermore, it is widely accepted that the functionality of HDL subclasses defines the antiatherogenic quality of HDL [17]. The heterogeneity of HDL particles in terms of shape, size and apolipoprotein composition was shown to determine their ability to inhibit LDL oxidation and reduce migration of monocytes within the arterial wall $[18,19]$. Dysfunctional HDL loses the function of reverse cholesterol transport and might exhibit pro-inflammatory, pro-oxidant, pro-thrombotic and proapoptotic properties, all responsible for the subsequent endothelial dysfunction [19, 20].

However, we still need a direct method to measure dysfunctional HDL, as currently we use many indirect methods, including the ones concerning the analysis of subfractions/subpopulations of lipoproteins [18, 19]. Recently, by means of one of these methods-an electrophoretic method (using LipoPrint system, Quantimetrix, USA), a new clinical phenomenon, atherogenic normolipidemia, has been described in healthy volunteers with no sign of overt CV disease [21, 22]. Despite normal levels of LDL-C, these subjects were still at a high CV risk due to high levels of sdLDL (LDL3-7 subfractions). So, both the "quality" and the "quantity" of plasma lipids and lipoproteins seem to essentially influence CV risk [23].

Statin therapy update 2013

Despite well-established roles in primary and secondary prevention of CVD, due to their positive effects on the plasma lipid profile, statin use is associated with some side effects and residual risk [24]. Beyond their potent pharmacologic inhibition of cholesterol biosynthesis, statins appear to have pleiotropic effects, including antiarrhythmic, antiinflammatory, antioxidative, antithrombotic, antimitotic, antibacterial, C reactive protein-lowering, angiogenic, immunomodulatory and vascular protective (stabilization of the atheroma plaque) activity, inhibition of smooth muscle cell proliferation and migration, inhibition of cardiac remodeling, inhibition of matrix metalloproteinase and cyclooxygenase- 2 , inhibition of telomere shortening, and improvement of microvascular function (amelioration of endothelial function) and of autonomic nervous system function [25-27]. Through modulation of many known and unknown pathways, statins may influence a wide range of diseases such as heart failure, hypertension, atrial fibrillation, diabetes mellitus, CKD and cancer [28, 29].

\section{Statins and new onset diabetes (NOD)}

The first meta-analysis that revealed that statin therapy for a mean follow-up of 4 years was associated with a higher incidence (by $9 \%$ ) of NOD was published in 2010 [30]. Then, the next meta-analysis that included over 57,000 participants demonstrated an even higher, $13 \%$ increase in the risk of NOD [31]. A careful review of findings from combined trials showed that statins can modestly raise blood glucose, and more patients who are on statin therapy are diagnosed with diabetes mellitus compared with those not on statins [32]. In February 2012, the Food and Drug Administration (FDA) released changes to statin safety label to include that statins have been associated with increases in hemoglobin A1C and fasting serum glucose levels. Furthermore, estimated risk of NOD from statin treatment is approximately one in 255-498 patients over 4 years [31-33]. At the same time, the number of patients needed to treat with highdose statin therapy to prevent one CV event was 155 (2-3.5 times less than the risk of NOD) [31, 34]. There is still discussion on the possible mechanisms of prodiabetic role of statins. Statins may affect molecular mechanisms that adversely impact on insulin sensitivity and beta-cell function, thereby increasing risk of NOD $[35,36]$. Recently, a retrospective cohort study examined the incidence of NOD in primary care patients treated 
with statins also observed an increased risk of NOD in these patients [37]. A population-based case-control study in women from an Asian country found out that the risk of statin-related NOD was more evident in women aged 40-64 years compared with women aged 65 or more and was cumulative dose-dependent [38]. Another population-based study evaluated the risk of incident diabetes in more than 1.5 million older patients from Canada, treated with statins [39]. They found that, compared with pravastatin, treatment with atorvastatin, rosuvastatin or simvastatin, but not fluvastatin or lovastatin, was associated with an increased risk of incident diabetes in statin-naive older patients without diabetes [40]. On the contrary, another study that evaluated the risk of incident $\mathrm{DM}$ in relation to statin prescription in 4,750 hypertensive, non-diabetic outpatients showed that in real-life outpatient environment, statin prescription for primary prevention is not associated with increased risk of incident DM [41].

Because diabetes is a risk equivalent condition for vascular diseases, recent findings create a paradox whereby needed statin therapy may be withheld to avoid excess risk of diabetes, while representing the strongest cardiovascular risk reduction tool in diabetics [34, 41]. Therefore, the experts in the field of lipid disorders have recently recommended the statin-associated risk of NOD appears to be unrelated to specific statins, but it seems to be dosedependent [34]. They also indicate some risk factors increasing the risk of NOD in patients treated with statins. Changes in the LDL-C concentration do not influence the risk of NOD, but older age, higher baseline fasting glucose levels and other features of metabolic syndrome [42] are the strongest predictors of NOD [34]. Some studies also suggest that women, the elderly and the Asians are at particularly higher risk of NOD $[34,36]$. There is also no doubt that statins should be used in secondary prevention patients, as the $\mathrm{CV}$ benefits significantly outweigh the risk of NOD [34, 36]. However, it is still questionable whether statins should be used for primary prevention among patients with a relatively low baseline $\mathrm{CV}$ risk (and with risk factors for diabetes). In these patients, it is recommended to use all possibilities of non-pharmacological therapy, and introducing statins should be considered individually after careful estimation of CV risk and treatment adverse events risks, when non-pharmacological therapy is not effective [34, 36, 43].

\section{Statin use in hypertensive patients}

Hypertension and hyperlipidemia often coexist and seem to be interrelated through common pathophysiological pathways [44]. The role of statins in controlling blood pressure (BP) in patients with hypertension has been controversial.
There are several mechanisms by which statins could influence and modify BP values: increasing the production of nitric oxide (NO), inhibition of the production of reactive oxygen species (ROS), reducing large artery stiffness and improving systemic arterial compliance [45-50]. Until now, some studies indicated the possibility of BP lowering with statins, whereas others did not $[47,51]$. On the basis of data from the available studies, it appears consistent that statins are useful in hypertensive patients irrespective of lipid profile, especially in patients with concomitant risk factors or CAD, as they significantly decrease the risk of all major cardiovascular outcomes (especially in secondary prevention, without the influence on all-cause mortality in the primary prevention) $[47,52]$. The recent meta-analysis of randomized controlled trials that studied the effects of statins on blood pressure in normotensive or hypertensive subjects provided reliable evidence against any substantial BP-lowering effect of statins in both normotensive and hypertensive patients, suggesting that the established protective effects of these drugs on the CV system do not materially depend on reductions in BP $[53,54]$.

\section{Statin use in chronic kidney disease patients}

CKD is associated with CVD even in the early stages, and a large number of patients die before developing advanced CKD [26, 55-58]. The available data suggest that efforts to reduce mortality in the CKD population should be focused on treatment and prevention of, among others, CAD and congestive heart failure [58-61]. In the ESC/EAS 2011 guidelines, it is clearly stated that CKD patients should be automatically treated as subjects at very high or high total cardiovascular risk who need active management of all risk factors [2]. A Lipid and Blood Pressure Meta-analysis Collaboration (LBPMC) Group meta-analysis of randomized controlled trials showed that statin therapy significantly modifies the lipid profile in CKD patients not on dialysis therapy (with the trend to be more effective with longer therapy) and have less beneficial effect in patients on dialysis with the trend to be less effective with longer duration of therapy (and even with some harmful effects such as TG increase and HDL-C reduction) [62]. Another meta-analysis from the same group that included 6,452 CKD subjects randomized to receive either statin or placebo studied the role of statins on renal outcomes [63]. It was observed that statins might exert significant renoprotective effects in CKD patients depending on the duration of treatment (especially on urinary protein, serum creatinine and glomerular filtration rate up to 3 years), but only in patients without dialysis therapy [63]. Another meta-analysis of 11 randomized controlled trials involving 21,295 participants showed that statins decrease all-cause mortality only in CKD patients not requiring dialysis therapy [64]. 
The very recent position paper of International Atherosclerosis Society (IAS)_Global Recommendations for the Management of Dyslipidemia suggested that in CKD patients classified as moderately high risk, the optimal range of LDL-C should be $<100 \mathrm{mg} / \mathrm{dL}$ (2.6 mmol/L) [65]. The recently published attempt at recommendation on statin use in patients with CKD suggests that CKD patients not requiring dialysis should be treated with statins for high $\mathrm{CV}$ risk and that the duration of treatment is particularly important for optimization of its effects [66]. It is also suggested that on the basis of available data, we cannot recommend initiating statin treatment in CKD patients requiring dialysis. However, on the other hand, we do not have enough data to stop treatment in patients who are already on statins [66]. This is the same stance that the KDIGO Work Group has taken as far as which particular patient population should receive statins [3, 4]. In contrast, however, and as previously noted, KDIGO recommended against the use of LDL-C for identifying CKD patients who should receive statins and also recommended that it is unnecessary to measure LDL-C in situations in which the results would not alter management decisions, e.g., those already receiving a statin (or in whom statin treatment is clearly indicated or not indicated based on changes in their cardiovascular risk profile or clinical status) would not require follow-up measurements of LDL-C [3, 4].

\section{PCSK9 inhibitors}

Insights from randomized controlled trials in patients with heart failure, atrial fibrillation and CKD suggest that there are still some questions regarding the role of statins in these conditions [67]. Statins activate LDL receptor (LDLR) gene expression, but also activate the expression of proprotein convertase subtilisin/kexin type 9 (PCSK9), a secreted inhibitor of LDLR, thereby limiting their beneficial effects [68]. PCSK9 is a serine protease expressed predominantly in the liver, intestine and kidney [69]. PCSK9 directly binds to the epidermal growth factor-like repeat A domain of the LDL receptor and induces its degradation, thereby controlling circulating LDL-C concentration [70, 71]. Recently, PCSK9 inhibition seems to be an attractive as a new strategy for lowering LDL-C levels, especially in combination with lipid-lowering drugs such as statins [72]. A new study that highlights differences in PCSK9 variants among Caucasian and African Canadians showed the PCSK9 gene to be highly polymorphic, with more than 50 exonic variations documented to have opposing effects on LDLC levels [73].

PCSK9 is able to induce degradation of the LDLRrelated protein 1 (LRP-1), and although the latter is not an essential factor for LDLR regulation, the LDLR effectively competes with LRP-1 for PCSK9 activity. Identification of
PCSK9 targets should allow a better understanding of the consequences of PCSK9 inhibition for lowering LDL-C [74]. Inhibition of the interaction between PCSK9 and the LDLR with monoclonal antibodies (mAbs) targeting PCSK9 has a great potential for patients with hypercholesterolemia (from the high risk groups), including familial hypercholesterolemia, as well as in patients with statin intolerance. Early clinical phase studies suggest that PSCK9 inhibitors given subcutaneously two or four times a month (both in monotherapy and in the combination with statin) are very effective reducing the baseline LDL-C even by $75 \%$ and well tolerated [75-77]. However, further studies with longer follow-up (current observations were usually up to 12 weeks) with the analysis of PCSK9inhibitors effect on primary and secondary endpoints $(\mathrm{CV}$ and mortality outcomes) are required to finally assess their efficacy and safety profile of this drugs [75, 78].

\section{Blood pressure update 2013}

The American College of Cardiology Foundation (ACCF)/American Heart Association (AHA) 2011 expert consensus document on hypertension in the elderly developed in collaboration with the American Academy of Neurology, American Geriatrics Society, American Society for Preventive Cardiology, American Society of Hypertension, American Society of Nephrology, Association of Black Cardiologists and European Society of Hypertension recommended that the BP should be lowered to less than $140 / 90 \mathrm{mmHg}$ in adults with hypertension younger than 80 years at high risk of CV events [79]. On the basis of data from the Hypertension in the Very Elderly Trial (HYVET) [80], these guidelines recommended that for those who 80 years of age and older, the systolic BP should be reduced to $140-145 \mathrm{mmHg}$ if tolerated [79]. On the other hand, data from the subanalyses and other observational studies suggest that there might be some benefit in reducing systolic BP below $140 \mathrm{mmHg}$ (see also below) [81-88]. The choice of specific antihypertensive agents depends on efficacy, tolerability, presence of specific comorbidities and cost [79].

Dyslipidemia often coexists with hypertension, and statins should be always considered in hypertensive patients, especially with other $\mathrm{CV}$ risk factors and CAD (see above) [47, 89-92]. Control of BP and serum LDL-C may significantly reduce progression of angiographic CAD [13].

In 2013, there have been several studies searching for new biomarkers that correlate with hypertension complications, such as cardiotrophin 1 (CT-1) and procollagen III $\mathrm{N}$-terminal propeptide, which are early markers of left 
ventricular injury, as well as neutrophil gelatinase-associated lipocalin, which could be a sensitive marker of kidney function in elderly patients with hypertension [93, 94]. In many interesting papers published last year, the authors not only evaluated the biomarkers, but also analyzed the type of hypertension. It was, among other, showed that a nondipping BP pattern might be responsible for development of left ventricular hypertrophy in patients with hypertension [95].

There have been also studies looking at improved control of hypertension, which remains as a large problem in both Europe and the US [96-98]. The Kaiser Permanente Northern California Registry included 652,763 patients with hypertension [99]. Use of a hypertension program improved control of hypertension from 43.6 to $80.4 \%$ ( $p<0.001$ for trend) [99]. The prevalence of hospitalization attributable to hypertensive diseases among United States adults aged 35 and older increased in men and in women from 1980 to 2007 ( $p<0.001)$, especially in the Southern region of the United States [100].

In recent years, there is also a large discussion on cardiometabolic risk at children. It has been recently showed that persons with persistently increased BP from childhood to adulthood had significantly increased risk of carotid atherosclerosis [101]. This risk was decreased if increased BP during childhood resolved by adulthood [101].

2013 is a year with new data on brain (cerebrovascular) damage in hypertensive patients. 3,020 patients (mean age 63 years) with a recent lacunar stroke were randomized in an open-label trial to a systolic blood pressure of $130-149 \mathrm{mmHg}$ or of $<130 \mathrm{mmHg}$; patients with a systolic blood pressure of $127 \mathrm{mmHg}$ after 1 year had an insignificant $19 \%$ reduction in all-stroke compared WITH patients with a systolic blood pressure of $138 \mathrm{mmHg}$ after 1 year [102]. Further insights into this important issue will be provided by a new trial-Optimal Blood Pressure and Cholesterol Targets for Preventing Recurrent Stroke in Hypertensives (ESH-CHL-SHOT) — which starts recruiting patients this year [103]. But, on the basis of available trials, it seems that there is a linear relation between stroke outcomes and systolic blood pressure, without any J-curve relation $[104,105]$.

There were also some new guidelines published in 2013. The American Diabetes Association (ADA) 2013 guidelines recommend that diabetics with hypertension should have their systolic blood pressure reduced to less than $140 \mathrm{mmHg}$ [106]. A systolic blood pressure less than $130 \mathrm{mmHg}$ may be considered in younger patients with long life expectancy if achieved with few drugs and without side effects [106]. The drug regimen should include an angiotensin-converting enzyme inhibitor or angiotensin receptor blocker unless the patient is pregnant. In pregnant women with chronic hypertension, a suggested target blood pressure is $110-129 / 65-79 \mathrm{mmHg}$ [106]. The KDIGO guidelines for management of BP in patients with non-dialysis-dependent CKD published in December 2012 recommended that adults with CKD without diabetes mellitus [107] or with diabetes mellitus [108] with hypertension and albuminuria less than $30 \mathrm{mg}$ per $24 \mathrm{~h}$ should have their BP reduced to $\leq 140 / \leq 90 \mathrm{mmHg}$ with a class IB indication. If albuminuria greater than $30 \mathrm{mg}$ per $24 \mathrm{~h}$ is present in these patients, reduction in the BP to $\leq 130$ / $\leq 80 \mathrm{mmHg}$ has a class IID indication which we would not follow [107, 108]. The European Society of Hypertension (ESH)/European Society of Cardiology (ESC) 2013 guidelines for the management of hypertension [109] recommend reducing the systolic blood pressure to less than $140 \mathrm{mmHg}$ in all patients at low to moderate cardiovascular risk (class I indication), in patients with diabetes mellitus (class I indication), in patients with a prior stroke or transient ischemic attack (class IIa indication), in patients with coronary heart disease (class IIa indication) and in patients with diabetic or non-diabetic CKD (class IIa indication) [109]. In elderly patients younger than 80 years with a systolic blood pressure of $160 \mathrm{mmHg}$ or higher, the systolic blood pressure should be reduced to between 140 and $150 \mathrm{mmHg}$ (class I indication) with consideration of a systolic blood pressure less than $140 \mathrm{mmHg}$ (class IIb indication) [109]. In patients older than 80 years with a systolic blood pressure of $160 \mathrm{mmHg}$ or higher, the systolic blood pressure should be reduced to between 140 and $150 \mathrm{mmHg}$ provided they are in good physical and mental conditions (class I indication). A diastolic blood pressure target of less than $90 \mathrm{mmHg}$ is always recommended except in diabetics in whom a level less than $85 \mathrm{mmHg}$ is recommended (class I indication) [109]. These guidelines also recommend in resistant hypertensive patients withdrawing drugs if their antihypertensive effect is absent or minimal (class I indication), consider adding a mineralocorticoid receptor antagonist, amiloride or doxazosin if no contraindication exists (class IIa indication), and consider in truly drug resistant hypertension with BP confirmed by ambulatory blood pressure monitoring an invasive procedure such as renal denervation or baroreceptor stimulation (class IIb indication) [109].

However, it is worth emphasizing that we have still had very limited data on optimal BP levels in the elderly [110 113]. The REasons for Geographic and Racial Differences in Stroke (REGARDS) study is an observational study of risk factors for stroke [114]. This study included 4,181 persons aged 55-64 years, 3,767 persons aged 65-74 years, and 1,839 persons aged 75 years and older (mean 79.3 years). Median follow-up was 4.5 years for CVD (first occurrence of a coronary heart disease or stroke event), 4.5 years for CHD (non-fatal myocardial infarction or coronary heart disease death), 5.7 years for stroke and 6.0 years for all-cause 
mortality. The results from this study generated a hypothesis that for all patients older than 55 years, the recommended level of systolic blood pressure should be less than $140 \mathrm{mmHg}$ with optimal values possibly between 120 and $139 \mathrm{mmHg}$ [114].

In December 2013, the Joint National Committee Expert Panel (JNC 8) published their Evidence-Based Guideline for the Management of High Blood Pressure in Adults [115]. The most important changes from the preceding JNC 7 guidelines included the following:

- In patients 60 years of age or older who do not have diabetes or CKD, the goal blood pressure level is $<150 /$ $90 \mathrm{mmHg}$, whereas in patients $18-59$ years of age without major comorbidities, and in patients 60 years of age or older who have diabetes, CKD or both, the goal blood pressure is $<140 / 90 \mathrm{mmHg}$. In younger patients without major comorbidities, increased DBP is a more important $\mathrm{CV}$ risk factor than is increased SBP, whereas in patients 60 years of age and older SBP control remains the most important factor (as in JNC 7) [115];

- First-line and later-line treatments are now be limited to four classes of medications namely: thiazide-type diuretics, calcium channel blockers (CCBs), angiotensin-converting enzyme inhibitors (ACE-I) and angiotensin II receptor blockers (ARB). Second- and thirdline agents include higher doses or combinations of ACE-I, ARB, thiazides and CCBs [115];

- For black patients without CKD, initial choices of antihypertensives should include CCBs and thiazides instead of ACE-I. Use of ACE-I and ARB is recommended for all patients with CKD regardless of ethnic background, either as first-line therapy or in addition to first-line therapy [115];

- ACE-I and ARB should not be used in the same patient simultaneously. This has been supported by three trials, namely the ONgoing Telmisartan Alone and in combination with Ramipril Global Endpoint Trial (ONTARGET) [116], the Aliskiren Trial in Type 2 Diabetes Using Cardio-Renal Endpoints (ALTITUDE) [117] and the recently published the Veterans Affairs Nephropathy in Diabetes (VA-NEPHRON) [118] which showed that hyperkalemia was significantly higher with combination therapy than with monotherapy (6.3 vs. 2.6 events per 100 person-years; $p<0.001$ ), as was acute kidney injury (12.2 vs. 6.7 events per 100 person-years; $p<0.001)$. At a median follow-up of 2.2 years, there was no significant difference in the study's primary endpoint of renal disease progression or death between the monotherapy and combination therapy groups (152 vs. $132 ; p=0.30$ ). There was also no difference in cardiovascular events $[115,118]$.
- CCBs and thiazides should be used instead of ACE-I and ARB in patients over the age of 75 with impaired kidney function due to the risk of hyperkalemia, increased creatinine and further renal impairment [115].

Later, the American Society of Hypertension (ASH) and the International Society of Hypertension (ISH) issued separate guidelines from JNC 8 [119], with some important differences:

- They recommended that the start treatment threshold of $>150 / 90 \mathrm{mmHg}$ applies to patients 80 years or older.

- They also suggested different antihypertensives for initial therapy, based on the patients' race, age and blood pressure level. They recommended an ACE-I or ARB for non-black patients under age 60 years of age, and a CCB or thiazide-type diuretic for non-black patients over 60 years of age. For black patients, they recommended a $\mathrm{CCB}$ or thiazide-type diuretic. In patients with blood pressure of at least 160/100, they recommended starting with two drugs from the start and they also had separate drug recommendations for special populations.

Several noteworthy trials on hypertension also deserve mention at this point. Over the past several years, renal angioplasty and stenting of atherosclerotic renal artery stenosis (RAS) became a common procedure. Recently, however, two randomized trials; the ASTRAL [120] and STAR [121] trials have failed to show any benefit. In December 2013, the results of CORAL trial [122] were published and demonstrated no difference in the primary and composite endpoints of death, myocardial infarctions, stroke, heart failure, progression of $\mathrm{CKD}$ and need for RRT. The only exception was for that of BP in which a significant but minor $(2 \mathrm{mmHg})$ drop in the intervention arm [122]. Therefore, for the majority of patients with RAS and either hypertension or CKD, management of RAS should be limited to medical therapy. Nevertheless, it remains to be seen if certain patients might still obtain some benefit from this procedure, e.g., those with severe stenosis to a single functioning kidney or those with severe stenosis and AKI and those presenting with flash pulmonary edema [120-122].

With the burden of resistant hypertension, the concept of renal denervation has been introduced. This is based on the premise that in patients with resistant hypertension, there is overstimulation of the sympathetic nervous system, i.e., afferent signaling from the kidneys increases central sympathetic drive, while efferent signals to the kidneys increase renin release and sodium retention, while reducing renal blood flow. Catheter-based renal denervation cuts this communication between the kidneys and the sympathetic 
nervous system, and theoretically will result in lowering of blood pressure [123, 124]. The Catheter-Based Renal Sympathetic Denervation for Resistant Hypertension: A Multicenter Safety and Proof-of-Principle Cohort Study (SYMPLICITY HTN-1) [123] involving 45 patients was published in 2009, followed by the renal sympathetic denervation in patients with treatment-resistant hypertension trial (SYMPLICITY HTN-2 in 2010) [124], involving 106 patients, and both studies showed a significant decrease in BP in a select group of patients with resistant hypertension subjected to catheter-based renal denervation. However, the pivotal the Renal Denervation in Patients With Uncontrolled Hypertension trial (SYMPLICITY-3) [125] (initiated recruitment in 2011) which randomized 535 patients was abruptly discontinued in January 2014, as it allegedly failed to show that treatment with the novel procedure resulted in a sustained reduction in systolic blood pressure [125]. According to the company, no safety (the primary safety endpoint was the incidence of major adverse events that occurred one month after treatment until six months) issues arose during the study [126].

\section{Kidney update 2013}

\section{Screening and kidney disease}

In October 2013, the American College of Physicians (ACP) published guidelines [127] to present the evidence and provide clinical recommendations on the screening, monitoring and treatment of adults with stage 1-3 CKD. This included four recommendations, which are the following:

- ACP recommended against screening for $\mathrm{CKD}$ in asymptomatic adults without risk factors for CKD (grade: weak recommendation, low-quality evidence);

- ACP recommended against testing for proteinuria in adults with or without diabetes who are currently taking an ACE-I or ARB (grade: weak recommendation, lowquality evidence);

- ACP recommended that clinicians select pharmacologic therapy that includes either an ACE-I (moderatequality evidence) or an ARB (high-quality evidence) in patients with hypertension and stage 1-3 CKD (grade: strong recommendation);

- ACP recommended that clinicians choose statin therapy to manage increased low-density lipoprotein in patients with stage 1-3 CKD (grade: strong recommendation, moderate-quality evidence) [127].

While the American Society of Nephrology (ASN) agreed with most of the above recommendations from ACP as they did reflect current standard clinical practice, they expressed disagreement with the ACP's recommendation against screening for CKD in asymptomatic adults without risk factors as well as the recommendation not to test for proteinuria in adults with or without diabetes who were already being treated with either an ACE-I or ARB [128]. ASN President Bruce Molitoris opined that "If detected early in its progression, kidney disease can be slowed and the transition to dialysis delayed. This evidence-based fact is why regular screening and early intervention by a nephrologist is so important to stemming the epidemic of kidney disease in the United States and why ASN strongly recommends it." This remains a controversial topic for debate in the years to come [128].

\section{Bone and the kidney}

A tendency toward phosphate retention begins early in renal disease, due to the reduction in the filtered phosphate load. Phosphate retention is intimately related to the common development of CVD risk in CKD, increased fibroblast growth factor (FGF)-23 levels and secondary hyperparathyroidism [129]. The Kidney Disease Improving Global Outcomes (KDIGO) guidelines on CKD-Mineral and Bone Disorder diagnostics and treatment were published in 2009 and emphasize the need of phosphate measurements during the course of disease [130]. Phosphate binders in use for treatment of chronic hyperphosphatemia are generally categorized as calcium-containing (mostly calcium carbonate and calcium acetate) and noncalcium-containing (including sevelamer and lanthanum). As noted in the KDIGO guideline, all are effective in lowering phosphate. There is no consensus about whether any particular phosphate binder should be used in patients with CKD.

However, clinicians are becoming more cautious with the use of calcium-containing phosphate binders because of concerns about toxicity of calcium accumulation associated with vascular calcification or adynamic bone disease. The decision to use non-calcium-containing binders over calcium-containing binders was for many years a subject of debate. In a recent meta-analysis of 11 open-label trials (4,622 patients) revealed a 22 percent decrease in all-cause mortality among patients with CKD randomly assigned to receive non-calcium-based phosphate binders [131]. These results are of particular interests because there aren't many strategies to improve mortality in CKD patients.

Given that the current approach to management of hyperphosphatemia is not always optimal, a number of alternative therapies are undergoing evaluation. These include colestilan and iron-containing phosphate binders. Colestilan is an anion exchanger compound with some similarities to sevelamer, initially being approved for the treatment of hypercholesterolemia. Recently, it has been 
successfully used as a phosphate binder for patients on dialysis in a phase III study, with similar effects compared with sevelamer or calcium-containing phosphate binders [132] in connection with significant lipid-lowering effects. However, data regarding mortality or other hard endpoints related to colestilan treatment in CKD patients are lacking.

Iron-containing phosphate binders represent other new alternatives in the treatment of hyperphosphatemia. Two molecules are most promising: iron(III)-oxyhydroxidebased phosphate binder (PA21) and ferric citrate, both being the subject of ongoing phase III studies. Even if appears that both products have similar efficiency with other phosphate binders with a lower pill burden, side effect profile and cost effectiveness remain to be evaluated $[133,134] .^{1,2}$

\section{Acute kidney injury}

The administration of radiocontrast media can lead to a usually reversible form of acute kidney injury (AKI) that begins soon after the contrast is administered [135]. Since there is no specific treatment once contrast-induced acute kidney injury (AKI) develops, the best treatment for contrast-induced kidney injury remains prevention. Traditionally, acetylcysteine or volume expansion using saline or sodium bicarbonate was the only methods proved to prevent contrast nephropathy. However, a variety of other interventions have been tried, including remote ischemic preconditioning. The latter is a method by which the deliberate induction of transient non-lethal ischemia of an organ protects against subsequent ischemic injury of another organ. The pathophysiological mechanism of remote ischemic preconditioning relies on a common final signaling pathway on the mitochondria. The mechanisms by which this occurs have been extensively investigated and involve signalling pathways in the mitochondria that prevent cell death [136]. Conditioning is currently being investigated in a number of clinical scenarios including renal protection.

An earlier randomized trial demonstrated that transient arm ischemia induced by intermittent blood pressure cuff inflation prior to contrast administration conferred protection against contrast nephropathy [137]. A second randomized trial in over 200 patients with a non-ST-segment increase myocardial infarction found that remote ischemic preconditioning induced by intermittent balloon catheter

\footnotetext{
${ }^{1}$ First phase II study report on polynuclear iron(III)-oxyhydroxide phosphate binder (PA21) in hyperphosphatemic hemodialysis patients.

2 Prospective, phase III, multicenter, open-label, randomized clinical trial using ferric citrate in hyperphosphatemic hemodialysis patients.
}

inflation at the time of percutaneous coronary intervention resulted in a lower rate of acute kidney injury [138].

\section{Mortality risk with hydroxyethyl starch solution (HES)}

Administration of intravenous fluids for volume expansion is very common in critically ill patients, particularly in the early stages of sepsis or during the perioperative period. A recent report of US Food and Drug Administration (FDA) indicates a higher risk of renal injury and mortality in critically ill patients treated with HES. The report recommends not using HES therapy in patients with preexisting renal dysfunction and to stop HES therapy at first sign of renal failure or coagulopathy. As HES fluids have higher associated costs than crystalloids, it seems reasonable to conclude that such fluids should not be used in critically ill patients [139].

\section{Novel agent for treatment of hyperkalemia}

A recent paper [140] questioned the rationale on the timehonored use of sodium polystyrene sulfonate (SPS), in the treatment of hyperkalemia, especially in light of the FDA warning issued in 2009, alluding to reports of colonic necrosis secondary to concomitant administration with sorbitol. The investigators found neither convincing evidence that SPS increased fecal potassium losses nor evidence that adding sorbitol increased its effectiveness. In November 2013, during the ASN Kidney Week, the company ZS Pharma presented the results of a phase II clinical trial of a novel potassium binder called ZS-9 (zirconium silicate), which was shown to be potentially capable of lowering potassium with minimal side effects [141, 142]. Now in phase III, ZS-9 is a highly selective oral sorbent (inorganic crystal) that selectively traps potassium ions over other ions throughout the gut. Interestingly, in in vitro studies, it was demonstrated to have a binding capacity of up to $3.5 \mathrm{mEq}$ of potassium per gram. Its selectivity and unique structure allow it to be potentially effective and safe in rapidly removing excess potassium and maintaining normal levels with a relatively low drug burden [141, 142].

\section{Chronic kidney disease}

\section{New anemia drugs in $C K D$}

Peginesatide is a synthetic peptide, attached to polyethylene glycol ("PEGylated") [143] which mimics the structure of erythropoietin. It was approved in 2012 by the U.S. Food and Drug Administration for treatment of anemia associated with CKD in adult patients on dialysis [144]. The use of peginesatide was supported by two randomized studies: the EMERALD study in which peginesatide was 
not inferior to epoetin for patients receiving dialysis and the PEARL study in which peginesatide administered once monthly was compared with darbopoetin twice monthly with no differences regarding efficiency in non-dialyzed patients [145]. However, cardiovascular events and mortality were increased with peginesatide in patients with CKD who were not undergoing dialysis [146]. Furthermore, roughly $0.2 \%$ of the 25,000 patients receiving the drug since its approval have experienced hypersensitivity reactions. Therefore, peginesatide has been voluntarily recalled by the manufacturers after these reports of anaphylaxis leading to three deaths.

\section{Tolvaptan and liver damage}

Tolvaptan is a selective, competitive vasopressin receptor 2 antagonist used to treat hyponatremia associated with congestive heart failure, cirrhosis and the syndrome of inappropriate antidiuretic hormone (SIADH). It was also demonstrated that it could be beneficial in the treatment for polycystic kidney disease by decreasing cAMP levels, inhibit cystogenesis [147]. According to a recent FDA alert, tolvaptan should not be used for more than 30 days or in patients with underlying liver disease. These patients are at increased risk of severe liver injury (potentially requiring liver transplantation) or death, according to the report.

\section{Dialysis in the elderly}

In our days, dialysis is widely available determining the nephrologists to consider its application in every patient in whom it might be indicated. Furthermore, the proportion of aged patients entering dialysis is fasting increasing over time. Overall, the initiating of dialysis in patients older than 70 years is associated with a better outcome as noted in a recent large retrospective study. However, the survival benefit was not observed among patients older than 80 years or among those with significant comorbidities. In addition, dialyzed patients were more prone to be hospitalized compared with patients on conservative care, which could have a negative impact on quality of life [148].

Transplantation

\section{Immunosuppression and risk of polyomavirus $B K$ nephropathy}

The human polyomaviruses $\mathrm{BK}$ are highly prevalent in humans but appear to cause clinical disease only in immunocompromised patients. BK virus primarily causes tubulointerstitial nephritis and ureteral stenosis in renal transplant with a medium reported prevalence of $5 \%$ [149]. Hirsch and colleagues recently investigated the incidence of BKV replication in more than 600 de novo kidney transplant recipients who were randomly assigned to receive either tacrolimus or cyclosporin A. All patients received basiliximab induction therapy as well as mycophenolic acid and prednisone. According to the authors, the risk of polyomavirus $\mathrm{BK}$ viremia $(\mathrm{BKV})$ in kidney transplant recipients was increased by high steroid exposure early after transplantation, treatment with tacrolimus rather than cyclosporin A, older donor age and male gender [150]. These results could be the result of a pharmacological interaction between steroid and tacrolimus, which might occur as a result of steroid-induced activation of cytochrome P450 3A and/or P-glycoprotein-enzymes that have a role in tacrolimus metabolism. Furthermore, cyclosporin A has been shown to suppress BKV replication in vitro but whether such effect is cell-specific and/or sufficient to offset the immunosuppressive properties of the agent in vivo is not known [151].

\section{New guidelines on the management of $C M V$}

Cytomegalovirus (CMV) remains one of the most common complications affecting organ transplant recipients, with significant morbidity, graft loss and occasional mortality [152]. The Transplantation Society International Cytomegalovirus (CMV) Consensus Group has published in 2013 new consensus guidelines on the management of CMV in solid-organ transplantation [153]. The guidelines discuss the immunology, prevention, treatment, drug resistance and pediatric-specific issues associated with CMV infection. These are the most important recommendations:

- Quantitative nucleic acid amplification testing (QNAT) is preferred for diagnosis, decisions regarding preemptive therapy and monitoring response to therapy due to the ability to harmonize and standardize these tests (strong, moderate). If QNAT is not available, antigenemia is an acceptable alternative; viral culture of blood or urine has a very limited role for the diagnosis of disease.

- Valganciclovir is increasingly used as the preferred agent for treatment. Additional specific recommendations on the use of IVIG with CMV treatment are included.

- Diagnostic resistance mutations have been updated, and the clinical management algorithm for ganciclovirresistant $\mathrm{CMV}$ has been slightly modified to clarify decision-making criteria.

- In the pediatrics section, valganciclovir is included in the prevention and treatment of CMV due to new data detailing the pharmacokinetics of valganciclovir in pediatrics [153]. 


\section{Conflict of interest None.}

Open Access This article is distributed under the terms of the Creative Commons Attribution License which permits any use, distribution, and reproduction in any medium, provided the original author(s) and the source are credited.

\section{References}

1. Banach M, Rysz J (2010) Current problems in hypertension and nephrology. Expert Opin Pharmacother 11(16):2575-2578

2. Catapano AL, Reiner Z, De Backer G, Graham I, Taskinen MR, Wiklund O, Agewall S, Alegria E, Chapman M, Durrington P, Erdine S, Halcox J, Hobbs R, Kjekshus J, Filardi PP, Riccardi G, Storey RF, Wood D (2011) European Society of Cardiology (ESC); European Atherosclerosis Society (EAS). ESC/EAS Guidelines for the management of dyslipidaemias The Task Force for the management of dyslipidaemias of the European Society of Cardiology (ESC) and the European Atherosclerosis Society (EAS). Atherosclerosis 217(1):3-46

3. Tonelli M, Wanner C; for the Kidney Disease: Improving Global Outcomes Lipid Guideline Development Work Group Members (2014) Lipid management in chronic kidney disease: synopsis of the kidney disease: improving global outcomes 2013 clinical practice guideline. Ann Intern Med. doi:10.7326/M13-2453

4. KDIGO (2013) clinical practice guideline for lipid management in chronic kidney disease. Kidney Int Suppl 3:259-305

5. Stone NJ, Robinson J, Lichtenstein AH et al (2014) 2013 ACC/ AHA guideline on the treatment of blood cholesterol to reduce atherosclerotic cardiovascular risk in adults: a report of the American College of Cardiology/American Heart Association Task Force on practice guidelines. Circulation. doi:10.1161/01. cir.0000437738.63853.7a

6. https://www.lipid.org/nla/2013-accaha-guideline-treatment-bloodcholesterol-reduce-atherosclerotic-cardiovascular-risk

7. EAS Guidelines Committee: New guidelines in USA: 2013 ACC/AHA Guidelines on the Treatment of Blood Cholesterol to Reduce Atherosclerotic Cardiovascular Risk. How do they compare with the EAS/ESC guidelines for the management of dyslipidaemia? http://us5.campaign-archive2.com/?u=5722525 cab46445583feb00fd\&id=4c6ab389e6\&e $=384788 \mathrm{f} 943$

8. Mark L, Paragh G, Karadi I, Reiber I, Pados G, Kiss Z (2012) How can we further improve the LDL-cholesterol target level achievement rate based on the Hungarian MULTI GAP 2011 study results and considering the new European dyslipidemia guidelines? Arch Med Sci 8(4):608-613

9. Mitka M (2013) Groups release new, updated guidelines to reduce heart disease risk factors. JAMA 310(24):2602-2604

10. Rizzo M, Banach M, Montalto G, Mikhailidis DP (2012) Lipidlowering therapies and achievement of LDL-cholesterol targets. Arch Med Sci 8(4):598-600

11. Rizzo M, Nikolic D, Banach M, Montalto G (2013) Statin treatment in the elderly: how much do we know? Arch Med Sci 9(4):585-588

12. Emerging Risk Factors C, Di Angelantonio E, Gao P, Pennells L, Kaptoge S, Caslake M et al (2012) Lipid-related markers and cardiovascular disease prediction. JAMA 307(23):2499-2506

13. Lai HM, Aronow WS, Mercando AD, Kalen P, Desai HV, Gandhi K, Sharma M, Amin H, Lai TM (2012) The impact of statin therapy on long-term cardiovascular outcomes in an outpatient cardiology practice. Arch Med Sci 8(1):53-56

14. Mark L, Paragh G, Karadi I, Reiber I, Pados G, Kiss Z (2011) An attempt to make lipid-lowering therapy more effective in
Hungary. The results of MULTI GAP 2010 and the PLUS Program. Arch Med Sci 2011(7):760-766

15. Wiklund O, Pirazzi C, Romeo S (2013) Monitoring of lipids, enzymes, and creatine kinase in patients on lipid-lowering drug therapy. Curr Cardiol Rep 15(9):397

16. Smith JD (2010) Dysfunctional HDL as a diagnostic and therapeutic target. Arterioscler Thromb Vasc Biol 30(2):151-155

17. Rothblat GH, Phillips MC (2010) High-density lipoprotein heterogeneity and function in reverse cholesterol transport. Curr Opin Lipidol 21(3):229-238

18. Rosenson RS, Brewer HB Jr, Chapman MJ, Fazio S, Hussain MM, Kontush A et al (2011) HDL measures, particle heterogeneity, proposed nomenclature, and relation to atherosclerotic cardiovascular events. Clin Chem 57(3):392-410

19. Otocka-Kmiecik A, Mikhailidis DP, Nicholls SJ, Davidson M, Rysz J, Banach M (2012) Dysfunctional HDL: a novel important diagnostic and therapeutic target in cardiovascular disease? Prog Lipid Res 51(4):314-324

20. Banach M, Hering D, Narkiewicz K, Mysliwiec M, Rysz J, Malyszko J (2012) Lipids, blood pressure, kidney-what was new in 2012? Int J Pharmacol 8:659-678

21. Oravec S, Dukat A, Gavornik P, Lovasova Z, Gruber K (2011) Atherogenic normolipidemia-a new phenomenon in the lipoprotein profile of clinically healthy subjects. Neuro Endocrinol Lett 32(3):317-321

22. Kucera M, Oravec S, Hirnerova E, Huckova N, Celecova Z, Gaspar L, Banach M (2014) Effect of atorvastatin on low density lipoprotein subpopulations and comparison between indicators of plasma atherogenicity-A pilot study. Angiology. doi:10.1177/0003319713507476

23. Mikhailidis DP, Elisaf M, Rizzo M, Berneis K, Griffin B, Zambon A et al (2011) "European panel on low density lipoprotein (LDL) subclasses": a statement on the pathophysiology, atherogenicity and clinical significance of LDL subclasses: executive summary. Curr Vasc Pharmacol 9(5):531-532

24. Paraskevas KI, Koupidis S, Gentimi F, Tzovaras AA (2011) Statin discontinuation: counterbalancing the benefits with the potential risks. Arch Med Sci 7(6):1076-1077

25. Swenne CA (2013) Beyond lipid lowering: pleiotropic effects of statins in heart failure. Neth Heart J 21(9):406-407

26. Olechnowicz-Tietz S, Gluba A, Paradowska A, Banach M, Rysz J (2013) The risk of atherosclerosis in patients with chronic kidney disease. Int Urol Nephrol 45(6):1605-1612

27. Kowalski J, Barylski M, Banach M, Grycewicz J, Irzmański R, Pawlicki L (2006) Neutrophil superoxide anion generation during atorvastatin and fluvastatin therapy used in coronary heart disease primary prevention. J Cardiovasc Pharmacol 48(4):143-147

28. Bielecka-Dabrowa A, Mikhailidis DP, Rizzo M, von Haehling S, Rysz J, Banach M (2013) The influence of atorvastatin on parameters of inflammation left ventricular function, hospitalizations and mortality in patients with dilated cardiomyopathy5-year follow-up. Lipids Health Dis 12(1):47

29. Lochhead P, Chan AT (2013) Statins and colorectal cancer. Clin Gastroenterol Hepatol 11(2):109-118

30. Sattar N, Preiss D, Murray HM, Welsh P, Buckley BM, de Craen AJ et al (2010) Statins and risk of incident diabetes: a collaborative meta-analysis of randomised statin trials. Lancet 375(9716):735-742

31. Rajpathak SN, Kumbhani DJ, Crandall J, Barzilai N, Alderman M, Ridker PM (2009) Statin therapy and risk of developing type 2 diabetes: a meta-analysis. Diabetes Care 32(10): 1924-1929

32. Shah RV, Goldfine AB (2012) Statins and risk of new-onset diabetes mellitus. Circulation 126(18):e282-e284 
33. Axsom K, Berger JS, Schwartzbard AZ (2013) Statins and diabetes: the good, the bad, and the unknown. Curr Atheroscler Rep 15(2):299

34. Banach M, Mikhailidis DP (2013) Statin therapy and new-onset diabetes: an attempt at recommendations. Exp Rev Endocrinol Metab 8(3):213-216

35. Banach M, Malodobra-Mazur M, Gluba A, Katsiki N, Rysz J, Dobrzyn A (2013) Statin therapy and new-onset diabetes: molecular mechanisms and clinical relevance. Curr Pharm Des 19(27):4904-4912

36. Barylski M, Nikolic D, Banach M, Toth PP, Montalto G, Rizzo M (2013) Statins and new-onset diabetes. Curr Pharm Des. doi:10.2174/13816128113196660678

37. Zaharan NL, Williams D, Bennett K (2013) Statins and risk of treated incident diabetes in a primary care population. Brit J Clin Pharmacol 75(4):1118-1124

38. Chen CW, Chen TC, Huang KY, Chou P, Chen PF, Lee CC (2013) Differential impact of statin on new-onset diabetes in different age groups: a population-based case-control study in women from an Asian country. PLoS One 8(8):e71817

39. Carter AA, Gomes T, Camacho X, Juurlink DN, Shah BR, Mamdani MM (2013) Risk of incident diabetes among patients treated with statins: population based study. BMJ 346:f2610

40. Izzo R, de Simone G, Trimarco V, Giudice R, De Marco M, Di Renzo G et al (2013) Primary prevention with statins and incident diabetes in hypertensive patients at high cardiovascular risk. Nutr Metab Cardiovasc Dis. doi:10.1016/j.numecd.2012.11.002

41. Sampson UK, Linton MF, Fazio S (2011) Are statins diabetogenic? Curr Opin Cardiol 26(4):342-347

42. Katsiki N, Banach M (2012) Statins and the risk of diabetes: the debate. Arch Intern Med 172(11):895-896

43. Athyros VG, Hatzitolios AI, Karagiannis A, Savopoulos C, Katsiki N, Tziomalos K, Papagianni A, Kakafika A, Gossios TD, Mikhailidis DP, IMPERATIVE Collaborative Group (2011) IMproving the imPlemEntation of cuRrent guidelines for the mAnagement of major coronary hearT disease rIsk factors by multifactorial interVEntion. The IMPERATIVE renal analysis. Arch Med Sci 7(6):984-992

44. Kostapanos MS, Milionis HJ, Elisaf MS (2010) Current role of statins in the treatment of essential hypertension. Expert Opin Pharmacother 11(16):2635-2650

45. Kalinowski L, Dobrucki IT, Malinski T (2002) Cerivastatin potentiates nitric oxide release and enos expression through inhibition of isoprenoids synthesis. J Physiol Pharmacol 53(4 Pt 1):585-595

46. John S, Schneider MP, Delles C, Jacobi J, Schmieder RE (2005) Lipid-independent effects of statins on endothelial function and bioavailability of nitric oxide in hypercholesterolemic patients. Am Heart J 149(3):473

47. Stepien M, Banach M, Mikhailidis DP, Gluba A, Kjeldsen SE, Rysz J (2009) Role and significance of statins in the treatment of hypertensive patients. Curr Med Res Opin 25(8):1995-2005

48. Banach M, Mikhailidis DP, Kjeldsen SE, Rysz J (2009) Time for new indications for statins? Med Sci Monit 15(12):MS1-5

49. Rikitake Y, Kawashima S, Takeshita S, Yamashita T, Azumi H, Yasuhara M et al (2001) Anti-oxidative properties of fluvastatin, an HMG-CoA reductase inhibitor, contribute to prevention of atherosclerosis in cholesterol-fed rabbits. Atherosclerosis 154(1):87-96

50. Aydin U, Ugurlucan M, Gungor F, Ziyade S, Inan B, Banach M et al (2009) Effects of atorvastatin on vascular intimal hyperplasia: an experimental rodent model. Angiology 60(3):370-377

51. Tycinska AM, Janica J, Mroczko B, Musial WJ, Sawicki R, Sobkowicz B, Kaminski K, Lebkowska U, Szmitkowski M (2011) Hypotensive effect of atorvastatin in hypertensive patients: the association among flow-mediated dilation, oxidative stress and endothelial dysfunction. Arch Med Sci 7(6):955-962

52. Feldstein CA (2010) Statins in hypertension: are they a new class of antihypertensive agents? Am J Ther 17(3):255-262

53. Katsiki N, Mikhailidis DP, Banach M (2011) Effects of statin treatment on endothelial function, oxidative stress and inflammation in patients with arterial hypertension and normal cholesterol levels. J Hypertens 29(12):2493-2494

54. Banach M, Nikfar S, Rahimi R, Bielecka-Dabrowa A, Pencina MJ, Mikhailidis DP, Lipid and Blood Pressure Meta-Analysis Collaboration Group et al (2013) The effects of statins on blood pressure in normotensive or hypertensive subjects - a meta-analysis of randomized controlled trials. Int J Cardiol 168(3):2816-2824

55. Gluba A, Mikhailidis DP, Lip GY, Hannam S, Rysz J, Banach M (2013) Metabolic syndrome and renal disease. Int J Cardiol 164(2):141-150

56. Franczyk-Skora B, Gluba A, Banach M, Rozentryt P, Polonski L, Rysz J (2013) Acute coronary syndromes in patients with chronic kidney disease. Curr Vasc Pharmacol 11(5):758-767

57. Stępien M, Stępien A, Wlazel RN, Paradowski M, Banach M, Rysz M, Rysz J (2013) Obesity indices and adipokines in nondiabetic obese patients with early stages of chronic kidney disease. Med Sci Monit 19:1063-1072

58. Franczyk-Skora B, Gluba A, Banach M, Rysz J (2013) Treatment of non-ST-elevation myocardial infarction and ST-elevation myocardial infarction in patients with chronic kidney disease. Arch Med Sci 9(6):1019-1027

59. Rysz J, Aronow WS, Stolarek RS, Hannam S, Mikhailidis DP, Banach M (2009) Nephroprotective and clinical potential of statins in dialyzed patients. Expert Opin Ther Targets 13(5):541-550

60. Athyros VG, Katsiki N, Tziomalos K, Gossios TD, Theocharidou E, Gkaliagkousi E, Anagnostis P, Pagourelias ED, Karagiannis A, Mikhailidis DP, GREACE Study Collaborative Group (2013) Statins and cardiovascular outcomes in elderly and younger patients with coronary artery disease: a post hoc analysis of the GREACE study. Arch Med Sci 9(3):418-426

61. Gluba A, Rysz J, Banach M (2010) Statins in patients with chronic kidney disease: why, who and when? Expert Opin Pharmacother 11(16):2665-2674

62. Nikolic D, Nikfar S, Salari P, Rizzo M, Ray KK, Pencina MJ, Lipid and Blood Pressure Meta-Analysis Collaboration Group et al (2013) Effects of statins on lipid profile in chronic kidney disease patients: a meta-analysis of randomized controlled trials. Curr Med Res Opin 29(5):435-451

63. Nikolic D, Banach M, Nikfar S, Salari P, Mikhailidis DP, Toth PP, Lipid and Blood Pressure Meta-Analysis Collaboration Group et al (2013) A meta-analysis of the role of statins on renal outcomes in patients with chronic kidney disease. Is the duration of therapy important? Int J Cardiol 168(6):5437-5447

64. Barylski M, Nikfar S, Mikhailidis DP, Toth PP, Salari P, Ray KK, Lipid and Blood Pressure Meta-Analysis Collaboration Group et al (2013) Statins decrease all-cause mortality only in CKD patients not requiring dialysis therapy - a meta-analysis of 11 randomized controlled trials involving 21,295 participants. Pharmacol Res 72:35-44

65. An International Atherosclerosis Society Position Paper: Global Recommendations for the Management of Dyslipidemia-Full Report. http://www.athero.org/download/IASPPGuidelines_Full Report_2.pdf

66. Banach M, Lipid, Blood Pressure Meta-Analysis Collaboration Group (2013) Statins in patients with chronic kidney diseasean attempt at recommendations. Curr Med Res Opin 29(11):1419-1422

67. Shekhar Pandey A, Bissonnette S, Boukas S, Rampakakis E, Sampalis JS (2011) Effectiveness and tolerability of ezetimibe 
co-administered with statins versus statin dose-doubling in highrisk patients with persistent hyperlipidemia: the EZE(STAT)2 trial. Arch Med Sci 7(5):767-775

68. Huijgen R, Boekholdt SM, Arsenault BJ, Bao W, Davaine JM, Tabet F et al (2012) Plasma PCSK9 levels and clinical outcomes in the TNT (Treating to New Targets) trial: a nested case-control study. J Am Coll Cardiol 59(20):1778-1784

69. Stein EA, Raal FJ (2013) Insights into PCSK9, low-density lipoprotein receptor, and low-density lipoprotein cholesterol metabolism: of mice and man. Circulation 127(24):2372-2374

70. Luna Saavedra YG, Zhang J, Seidah NG (2013) PCSK9 prosegment chimera as novel inhibitors of LDLR degradation. PloS One 8(8):e72113

71. Poirier S, Mayer G (2013) The biology of PCSK9 from the endoplasmic reticulum to lysosomes: new and emerging therapeutics to control low-density lipoprotein cholesterol. Drug Des Devel Ther 7:1135-1148

72. Banach M, Rizzo M, Obradovic M, Montalto G, Rysz J, Mikhailidis DP et al (2013) PCSK9 inhibition-a novel mechanism to treat lipid disorders? Curr Pharm Des 19(21):3869-3877

73. Mayne J, Ooi TC, Raymond A, Cousins M, Bernier L, Dewpura $T$ et al (2013) Differential effects of PCSK9 loss of function variants on serum lipid and PCSK9 levels in Caucasian and African Canadian populations. Lipids Health Dis 12:70

74. Canuel M, Sun X, Asselin MC, Paramithiotis E, Prat A, Seidah NG (2013) Proprotein convertase subtilisin/kexin type 9 (PCSK9) can mediate degradation of the low density lipoprotein receptor-related protein 1 (LRP-1). PLoS One 8(5):e64145

75. Catapano AL, Papadopoulos N (2013) The safety of therapeutic monoclonal antibodies: implications for cardiovascular disease and targeting the PCSK9 pathway. Atherosclerosis 228(1):18-28

76. Desai NR, Kohli P, Giugliano RP, O'Donoghue ML, Somaratne R, Zhou J, Hoffman EB, Huang F, Rogers WJ, Wasserman SM, Scott R, Sabatine MS (2013) AMG145, a monoclonal antibody against proprotein convertase subtilisin kexin type 9, significantly reduces lipoprotein(a) in hypercholesterolemic patients receiving statin therapy: an analysis from the LDL-C Assessment with Proprotein Convertase Subtilisin Kexin Type 9 Monoclonal Antibody Inhibition Combined with Statin Therapy (LAPLACE)-Thrombolysis in Myocardial Infarction (TIMI) 57 trial. Circulation 128(9):962-969

77. Koren MJ, Scott R, Kim JB, Knusel B, Liu T, Lei L, Bolognese M, Wasserman SM (2012) Efficacy, safety, and tolerability of a monoclonal antibody to proprotein convertase subtilisin/kexin type 9 as monotherapy in patients with hypercholesterolaemia (MENDEL): a randomised, double-blind, placebo-controlled, phase 2 study. Lancet 380(9858):1995-2006

78. Sullivan D, Olsson AG, Scott R, Kim JB, Xue A, Gebski V, Wasserman SM, Stein EA (2012) Effect of a monoclonal antibody to PCSK9 on low-density lipoprotein cholesterol levels in statin-intolerant patients: the GAUSS randomized trial. JAMA 308(23):2497-2506

79. Aronow WS, Fleg JL, Pepine CJ et al (2011) ACCF/AHA 2011 expert consensus document on hypertension in the elderly: a report of the American College of Cardiology Foundation Task Force on Clinical Expert Consensus Documents. Developed in collaboration with the American Academy of Neurology, American Geriatrics Society, American Society for Preventive Cardiology, American Society of Hypertension, American Society of Nephrology, Association of Black Cardiologists, and European Society of Hypertension. J Am Coll Cardiol 57:2037-2114

80. Beckett NS, Peters R, Fletcher AE et al (2008) Treatment of hypertension in patients 80 years of age or older. N Eng J Med 358:1887-1898
81. Aronow WS (2011) Hypertension guidelines. Hypertension 58:347-348

82. Aronow WS, Banach M (2012) Ten most important things to learn from the ACCF/AHA 2011 expert consensus document on hypertension in the elderly. Blood Press 21:3-5

83. Banach M, Michalska M, Kjeldsen SE et al (2011) What should be the optimal levels of blood pressure: does the J-curve phenomenon really exist? Expert Opin Pharmacother 12:1835-1844

84. Aronow WS (2012) What should the optimal blood pressure goal be in patients with diabetes mellitus or chronic kidney disease? Arch Med Sci 8:399-402

85. Banach M, Aronow WS (2011) Should we have any doubts about hypertension therapy in elderly patients. ACCF/AHA 2011 expert consensus document on hypertension in the elderly. Pol Arch Med Wewn 2011(121):253-258

86. Aronow WS (2014) Ten key points from the American College of Cardiology Foundation/American Heart Association 2011 expert consensus document on hypertension in the elderly. Am J Therap. doi:10.1097/MJT.Ob013e3182217894

87. Aronow WS (2012) Peripheral arterial disease of the lower extremities. Arch Med Sci 8:375-388

88. Banach M, Aronow WS (2012) Hypertension therapy in the elderly-do we know the answers to all the questions? The status after publication of the ACCF/AHA 2011 Expert Consensus Document on Hypertension in the Elderly. J Hum Hypertens 26:641-643

89. Barylski M, Malyszko J, Rysz J et al (2011) Lipids, blood pressure, kidney-what was new in 2011? Arch Med Sci 7:1055-1066

90. Egan BM, Li J, Qanungo S, Wolfman TE (2013) Blood pressure and cholesterol control in hypertensive hypercholesterolemic patients: national health and nutrition examination surveys 1988-2010. Circulation 128(1):29-41

91. Rizzo M, Montalto G, Banach M (2012) The effects of statins on blood pressure: current knowledge and future perspectives. Arch Med Sci 8:1-3

92. Gharipour M, Kelishadi R, Khosravi A et al (2012) The impact of a community trial on the pharmacological treatment in the individuals with the metabolic syndrome: findings from the Isfahan Healthy Heart Program, 2001-2007. Arch Med Sci 8:1009-1017

93. Malyszko J, Bachorzewska-Gajewska H, Malyszko J et al (2011) Markers of kidney function in the elderly in relation to the new CKD-EPI formula for estimation of glomerular filtration rate. Arch Med Sci 7:658-664

94. Gluba A, Bielecka-Dabrowa A, Mikhailidis DP, Wong ND, Franklin SS, Rysz J, Banach M (2012) An update on biomarkers of heart failure in hypertensive patients. J Hypertens 30(9):1681-1689

95. Mozdzan M, Wierzbowska-Drabik K, Kurpesa M et al (2013) Echocardiographic indices of left ventricular hypertrophy and diastolic function in hypertensive patients with preserved LVEF classified as dippers and non-dippers. Arch Med Sci 9:268-275

96. Bielecka-Dabrowa A, Aronow WS, Rysz J, Banach M (2011) The Rise and Fall of Hypertension: lessons Learned from Eastern Europe. Curr Cardiovasc Risk Rep 5(2):174-179

97. Dorobanţu M, Darabont R, Ghiorghe S, Arsenescu-Georgescu C, Macarie C, Mitu F, Lighezan D, Musetescu R, Pop C, Ardeleanu E, Craiu E (2014) T Latin Small Letter A With Caron Utu OF. Hypertension prevalence and control in Romania at a seven-year interval. Comparison of SEPHAR I and II surveys. J Hypertens 32(1):39-47

98. Stępień M, Wlazeł RN, Paradowski M, Banach M, Rysz M, Misztal M, Rysz J (2012) Serum concentrations of adiponectin, leptin, resistin, ghrelin and insulin and their association with 
obesity indices in obese normo- and hypertensive patients-pilot study. Arch Med Sci 8(3):431-436

99. Jaffe MG, Lee GA, Young JD et al (2013) Improved blood pressure control associated with a large-scale hypertension program. JAMA 310:699-705

100. Liu L, An Y, Chen M et al (2013) Trends in the prevalence of hospitalization attributable to hypertensive diseases among United States adults aged 35 and older from 1980 to 2007. Am J Cardiol 112:694-699

101. Juhola J, Magnussen CG, Berenson GS et al (2013) Combined effects of child and adult elevated blood pressure on subclinical atherosclerosis. The International Childhood Cardiovascular Cohort Consortium. Circulation 128:217-224

102. The SPS3 Study Group (2013) Blood-pressure targets in patients with recent lacunar stroke: the SPS3 randomised trial. Lancet 382:507-515

103. Zanchetti A, Liu L, Mancia G, Parati G, Grassi G, StrambaBadiale M et al (2013) Stroke in hypertension optimal treatment (SHOT) trial: protocol and organization. J Hypertens 31(e-Suppl A):e255

104. Malyszko J, Muntner P, Rysz J, Banach M (2013) Blood pressure levels and stroke-J-curve phenomenon? Curr Hypertens Rep 15(6):575-581

105. Siebert J, Gutknecht P, Molisz A, Trzeciak B, Nyka W (2012) Hemodynamic findings in patients with brain stroke. Arch Med Sci 8(2):371-374

106. American Diabetes Association. Position statement. Standards of Medical Care in Diabetes-2013. Diabetes Care 2013; 36(Suppl 1):S11-S66

107. KDIGO Clinical Practice Guideline for the Management of Blood Pressure in Chronic Kidney Disease. Chapter 3. Blood pressure management in CKD ND patients without diabetes mellitus. Kidney Int Suppl 2:357-362 (2012)

108. KDIGO Clinical Practice Guideline for the Management of Blood Pressure in Chronic Kidney Disease. Chapter 4. Blood pressure management in CKD ND patients with diabetes mellitus. Kidney Int Suppl 2:363-369 (2012)

109. Mancia G, Fagard R, Narkiewicz K et al (2013) 2013 ESH/ESC Guidelines for the management of arterial hypertension: the Task force for the management of arterial hypertension of the European Society of Hypertension (ESH) and of the European Society of Cardiology (ESC). J Hypertens 31:1281-1357

110. Gowin E, Avonts D, Horst-Sikorska W, Dytfeld J, Michalak M (2012) Stimulating preventive procedures in primary care. Effect of PIUPOZ program on the delivery of preventive procedures. Arch Med Sci 8(4):704-710

111. Alagiakrishnan K, Banach M, Jones LG, Ahmed A, Aronow WS (2013) Medication management of chronic heart failure in older adults. Drugs Aging 30(10):765-782

112. Rogowicz-Frontczak A, Araszkiewicz A, Pilacinski S, Zozulinska-Ziolkiewicz D, Wykretowicz A, Wierusz-Wysocka B (2012) Carotid intima-media thickness and arterial stiffness in type 1 diabetic patients with and without microangiopathy. Arch Med Sci 8:484-490

113. Chandy D, Aronow WS, Banach M (2013) Current perspectives on treatment of hypertensive patients with chronic obstructive pulmonary disease. Integr Blood Press Control 6:101-109

114. Banach M, Bromfield S, Howard G et al (2013) Optimal blood pressure levels in elderly persons in the Reasons for Geographic and Racial Differences in Stroke (REGARDS) cohort study. Presented at 2013 European Society of Cardiology (ESC) Meeting, Amsterdam, The Netherlands

115. James PA, Oparil S, Carter BL et al (2013) 2014 Evidence-based guideline for the management of high blood pressure in adults: report from the panel members appointed to the eighth joint national committee (JNC 8). JAMA. doi:10.1001/jama.2013.284427
116. Mann JF, Schmieder RE, McQueen M, ONTARGET Investigators et al (2008) Renal outcomes with telmisartan, ramipril, or both, in people at high vascular risk (the ONTARGET study): a multicentre, randomised, double-blind, controlled trial. Lancet 372(9638):547-553

117. Parving HH, Brenner BM, McMurray JJ, ALTITUDE Investigators et al (2012) Cardiorenal end points in a trial of aliskiren for type 2 diabetes. N Engl J Med 367(23):2204-2213

118. Fried LF, Emanuele N, Zhang JH, VA NEPHRON-D Investigators et al (2013) Combined angiotensin inhibition for the treatment of diabetic nephropathy. $N$ Engl J Med 369(20): 1892-1903

119. Weber MA, Schiffrin EL, White WB et al (2014) Clinical practice guidelines for the management of hypertension in the community: a statement by the American society of hypertension and the international society of hypertension. J Clin Hypertens (Greenwich) 16(1):14-26

120. ASTRAL Investigators, Wheatley K, Ives N, Gray R et al (2009) Revascularization versus medical therapy for renal-artery stenosis. N Engl J Med 361(20):1953-1962

121. Bax L, Woittiez AJ, Kouwenberg HJ et al (2009) Stent placement in patients with atherosclerotic renal artery stenosis and impaired renal function: a randomized trial. Ann Intern Med 150(12):840-848 (W150-1)

122. Cooper CJ, Murphy TP, Cutlip DE, CORAL Investigators et al (2014) Stenting and medical therapy for atherosclerotic renalartery stenosis. N Engl J Med 370(1):13-22

123. Krum H, Schlaich M, Whitbourn R et al (2009) Catheter-based renal sympathetic denervation for resistant hypertension: a multicentre safety and proof-of-principle cohort study. Lancet 373(9671):1275-1281

124. Esler MD, Krum H, Schlaich M, Symplicity HTN-2 Investigators et al (2012) Renal sympathetic denervation for treatment of drug-resistant hypertension: one-year results from the Symplicity HTN-2 randomized, controlled trial. Circulation 126(25):2976-2982

125. http://www.clinicaltrials.gov/ct2/show/NCT01418261?term= SYMPLICITY +HTN3\&rank=1

126. http://newsroom.medtronic.com/phoenix.zhtml?c=251324\&p= irol-newsArticle \&ID=1889335\&highlight $=\& u t m \_s o u r c e=$ MDT_com_Symplifybptrial_Home_Page\&utm_medium=Impt_ IInf_ReadPR_Link\&utm_campaign=Renal_Denervation_RDN_ Press_Release_010914

127. Qaseem A, Hopkins RH, Sweet DE, Starkey M, Shekelle P (2013) Screening, monitoring, and treatment of stage 1 to 3 chronic kidney disease: a clinical practice guideline from the clinical guidelines committee of the American college of physicians. Ann Intern Med. doi:10.7326/0003-4819-159-12201312170-00726

128. http://www.medscape.com/viewarticle/813082

129. Delmez JA, Slatopolsky E et al (1992) Hyperphosphatemia: its consequences and treatment in patients with chronic renal disease. Am J Kidney Dis 19(4):303

130. Kidney Disease: Improving Global Outcomes (KDIGO) CKDMBD Work Group (2009) KDIGO clinical practice guideline for the diagnosis, evaluation, prevention, and treatment of Chronic Kidney Disease-Mineral and Bone Disorder (CKD-MBD). Kidney Int Suppl S1

131. Jamal SA, Vandermeer B, Raggi P, Mendelssohn DC, Chatterley T, Dorgan M, Lok CE, Fitchett D, Tsuyuki RT (2013) Effect of calcium-based versus non-calcium-based phosphate binders on mortality in patients with chronic kidney disease: an updated systematic review and meta-analysis. Lancet 382(9900): 1268

132. Locatelli F, Dimkovic N, Pontoriero G et al (2010) Effect of MCI-196 on serum phosphate and cholesterol levels in haemodialysis patients with hyperphosphataemia: a double-blind, 
randomized, placebo-controlled study. Nephrol Dial Transpl 25:574-581

133. Wüthrich RP, Chonchol M, Covic A et al (2013) Randomized clinical trial of the iron-based phosphate binder PA21 in hemodialysis patients. Clin J Am Soc Nephrol 8:280-289

134. Dwyer JP, Sika M, Schulman G et al (2013) Collaborative Study GroupDose-response and efficacy of ferric citrate to treat hyperphosphatemia in hemodialysis patients: a short-term randomized trial. Am J Kidney Dis 61:759-766

135. Asif A, Epstein $M$ et al (2004) Prevention of radiocontrastinduced nephropathy. Am J Kidney Dis 44(1):12

136. Garlid KD, Costa ADT, Quinlan CL, Pierre SV, Dos Santos P (2009) Cardioprotective signaling to mitochondria. J Mol Cell Cardiol 46:858-866

137. Er F, Nia AM, Dopp H, Hellmich M, Dahlem KM, Caglayan E, Kubacki T, Benzing T, Erdmann E, Burst V, Gassanov N (2012) Ischemic preconditioning for prevention of contrast mediuminduced nephropathy: randomized pilot RenPro Trial (Renal Protection Trial). Circulation 126(3):296

138. Deftereos S, Giannopoulos G, Tzalamouras V, Raisakis K et al (2013) Renoprotective effect of remote ischemic post-conditioning by intermittent balloon inflations in patients undergoing percutaneous coronary intervention. J Am Coll Cardiol 61(19):1949-1955 (Epub 2013 Mar 14)

139. http://www.fda.gov/Safety/MedWatch/SafetyInformation/Safety AlertsforHumanMedicalProducts/ucm 358349.htm

140. Sterns RH, Rojas M, Bernstein P, Chennupati S (2010) Ionexchange resins for the treatment of hyperkalemia: are they safe and effective? J Am Soc Nephrol 21(5):733-735

141. http://www.zspharma.com/ZS-9.html

142. http://www.clinicaltrials.gov/ct2/show/NCT01493024?term=zs+ pharma\&rank $=1$

143. Stead RB, Lambert J, Wessels D, Iwashita JS, Leuther KK, Woodburn KW, Schatz PJ, Okamoto DM, Naso R, Duliege AM (2006) Evaluation of the safety and pharmacodynamics of Hematide, a novel erythropoietic agent, in a phase 1, double-blind, placebo-controlled, dose-escalation study in healthy volunteers. Blood 108(6): 1830-1834

144. Yao S (2012) FDA approves Omontys to treat anemia in adult patients on dialysis (press release). US FDA. Retrieved April 29, 2012
145. Fishbane S, Schiller B, Locatelli F, Covic AC, Provenzano R, Wiecek A, Levin NW, Kaplan M, Macdougall IC, Francisco C, Mayo MR, Polu KR, Duliege AM, Besarab A (2013) Peginesatide in patients with anemia undergoing hemodialysis. N Engl J Med 368(4):307-319

146. Macdougall IC, Provenzano R, Sharma A, Spinowitz BS, Schmidt RJ, Pergola PE, Zabaneh RI, Tong-Starksen S, Mayo MR, Tang H, Polu KR, Duliege AM, Fishbane S (2013) Peginesatide for anemia in patients with chronic kidney disease not receiving dialysis. N Engl J Med 368(4):320-332

147. Torres VE, Chapman AB, Devuyst O et al (2012) Tolvaptan in patients with autosomal dominant polycystic kidney disease. N Engl J Med 367:2407

148. Hussain JA, Mooney A, Russon L et al (2013) Comparison of survival analysis and palliative care involvement in patients aged over 70 years choosing conservative management or renal replacement therapy in advanced chronic kidney disease. Palliat Med 27(9):829-839

149. Hirsch HH, Knowles W, Dickenmann M, Passweg J, Klimkait T, Mihatsch MJ, Steiger J (2002) Prospective study of polyomavirus type BK replication and nephropathy in renal-transplant recipients. N Engl J Med 347(7):488

150. Hirsch HH, Vincenti F, Friman S et al (2013) Polyomavirus BK replication in de novo kidney transplant patients receiving tacrolimus or cysclosporine: a prospective, randomized, multicenter study. Am J Transpl 13(1):136-145

151. Acott PD, O'Regan PA, Lee HS, Crocke JF (2008) In vitro effect of cyclosporine A on primary and chronic BK polyoma virus infection in Vero E6 cells. Transpl Infect Dis 10:385-390

152. Pereyra F, Rubin RH (2004) Prevention and treatment of cytomegalovirus infection in solid organ transplant recipients. Curr Opin Infect Dis 17(4):357

153. Kotton CN, Kumar D, Caliendo AM et al (2013) Updated international consensus guidelines on the management of cytomegalovirus in solid-organ transplantation. Transplantation 96:333-360 